\title{
Young age increases the risk of lymph node positivity in papillary thyroid cancer patients: a SEER data-based study
}

This article was published in the following Dove Press journal: Cancer Management and Research

\author{
Jing Wang* \\ Jianjun Liu* \\ Huayuan Pan \\ Chenghao Jiang \\ Song Liu \\ Zhengzhi Zhu \\ Jing Fang \\ Xucai Zheng \\ Shikai Hong \\ Shengying Wang
}

Department of Head, Neck and Breast Surgery, The First Affiliated Hospital of the University of Science and Technology of China, Anhui Provincial Cancer Hospital, Hefei, People's Republic of China

*These authors contributed equally to this work
Correspondence: Shengying Wang Department of Head, Neck and Breast Surgery, The First Affiliated Hospital of the University of Science and Technology of China, Anhui Provincial Cancer Hospital, No. 107, West 2nd Ring Road, Hefei, 230000, People's Republic of China Email wangsy0387@I63.com
Introduction: Currently in papillary thyroid cancer (PTC), the correlation between lymph node positivity $(\mathrm{LN}+)$ and patient's age at diagnosis is still inconclusive. The aim of this study was to investigate whether younger PTC patients had higher LN+ rates.

Patients and methods: From the 1998-2013 Surveillance, Epidemiology, and End Results database, we analyzed PTC patients with at least $1 \mathrm{LN}$ examined. The patients were divided into 5 groups by age separately for each $T$ stage: $\leq 30 ; 31-40 ; 41-50 ; 51-60 ;>60$ years.

Results: A total of 46,077 PTC patients were identified, including 8,386 (18.2\%) patients aged $\leq 30$ years, 10,971 (23.8\%) patients aged 31-40 years, 11,646 (25.3\%) patients aged 41-50 years, 8,596 (18.7\%) patients aged 51-60 years, and 6,478 (14.1\%) patients aged $>60$ years. In each $\mathrm{T}$ stage, $\mathrm{LN}+$ rates were inversely associated with age at diagnosis, which was validated by multivariate logistic regression analysis $(p<0.001)$. In addition, the subset of patients 30 or younger had the highest lymph node ratio compared with other subsets $(p<0.001)$.

Conclusion: We identified that younger PTC patients have an increased predisposition for $\mathrm{LN}+$ regardless of $\mathrm{T}$ stage. This finding could help surgeons to select the optimal treatment for younger PTC patients.

Keywords: papillary thyroid cancer, age at diagnosis, lymph node positivity, lymph node ratio, recurrence, Surveillance, Epidemiology, and End results

\section{Introduction}

Due to advanced diagnostic level and periodic health screening, thyroid cancer has become the cancer with one of the highest incidences in America. ${ }^{1,2}$ Younger patients with papillary thyroid cancer (PTC) contribute a large proportion to this increasing trend. ${ }^{3}$ Despite the rate of survival for PTC being favorable, with $98 \%$ survival rate for the next 5 years, ${ }^{1}$ several studies demonstrated that the risk of recurrence ranges from $5 \%$ to $21 \%$ in PTC. ${ }^{4,5}$

Multiple risk factors were well known to be associated with recurrence and/or survival of PTC patients, including age at diagnosis, $\mathrm{T}$ stage, $\mathrm{N}$ stage, massive extrathyroid extension, BRAF mutation, and histological subtypes. ${ }^{6-9}$ For example, several reports identified that the number of positive lymph node (PLN) appears to predict the rate of recurrence in PTC. ${ }^{10,11}$ It is generally agreed that the $\mathrm{LN}+$ status is also affected by the patient's individual clinicopathologic characteristics in malignancies.

Patients' LN+ status was affected by the patients' age at diagnosis, which was demonstrated in carcinoma of the rectum, breast, and in melanomas. ${ }^{12-14}$ In 2016 in the analysis of 56,074 patients, Meyer et $\mathrm{al}^{12}$ had pointed out that young age at diagnosis 
was associated with increased $\mathrm{LN}+$ rates in early-stage rectal cancer. Similarly, Chao et $\mathrm{al}^{13}$ also showed that the incidence of sentinel LN+ declined with increasing age at diagnosis for melanoma. This pattern was also seen in the study of earlystage breast cancers by Anders et al. ${ }^{14}$

However, the correlation between $\mathrm{LN}+$ and patient's age at diagnosis in PTC is still inconclusive. While several studies claimed that young age at diagnosis could be an independent predictor of $\mathrm{LN}+,{ }^{15-19}$ one study showed that older PTC patients were more likely to exhibit higher LN+ rates, ${ }^{20}$ and another study did not find a correlation between age and $\mathrm{LN}+{ }^{21}$ Therefore, based on a large population dataset, we aimed to investigate whether younger PTC patients were associated with higher $\mathrm{LN}+$ rates.

\section{Patients and methods}

\section{Patients}

All the PTC patients who were diagnosed between 1988 and 2013 from the Surveillance, Epidemiology, and End Results (SEER) database were analyzed in current study. The SEER database is a national collaboration program set up by the National Cancer Institute of United States. It covers up to $26 \%$ of America's population, using 17 population-based cancer registries (totaling approximately 3 million cases).

Patients diagnosed with PTC were identified using histopathology codes of the International Classification of Diseases for Oncology, 3rd edition: 8050, 8260-8263, 8340-8344, 8450. Pathologically staged patients who underwent thyroidectomy with 1 or more LNs surgically examined and no evidence of distant metastasis were included. Patients who received radiotherapy prior to surgery or whose thyroid malignancy was not their first primary cancer were excluded.

\section{Statistical analyses}

Our analyses included demographic characteristics (race, sex, age at diagnosis), tumor characteristics ( $\mathrm{T}$ stage, LN+ status), and type of surgery. According to the SEER extent of disease extension codes for cases from 1988 to 2003, and the American Joint Committee on Cancer-derived T stage for cases from 2004 to 2008, T stage was categorized as T1, T2, T3, and T4. In addition, T1 group of the PTC patients was classified into T1 a and T1b, due to different histopathologic characteristics among them. ${ }^{22,23}$ Age was divided as a categorical variable using 10-year intervals, except for the group of ages $\leq 30$ and $>60$ years, because of the relatively smaller number of cases. The primary analysis of the study was $\mathrm{LN}+$ status. It was illustrated by $\mathrm{LN}+$ rates, number of PLN and lymph node ratio (LNR). The LNR was calculated as the ratio of number of PLN divided by the total number of lymph nodes examined. Trends in the mean number of PLN and LNR by age were evaluated using quantile regression models. Trends in $\mathrm{LN}+$ rates with age were evaluated with Cochran Armitage trend tests.

All data were analyzed by the SPSS version 21.0 (IBM Corporation, Armonk, NY, USA) and the R software version 3.13 (http://www.r-project.org/). A $p$-value $<0.05$ was considered to be statistically significant, and all the tests were 2 -sided.

\section{Ethical approval}

SEER data are deidentified before release and do not contain any personally identifying information. As the data is publicly available, no ethical approval is required.

\section{Results}

\section{Clinicopathologic characteristics of patients}

A total of 46,077 nonmetastatic PTC patients who received surgery between 1988 and 2013 were included in this study. The clinicopathologic characteristics of PTC were separated by age at diagnosis (Table 1). Overall, the mean age at diagnosis was $44.3 \pm 14.5$ years. A total of $8,386(18.2 \%)$ patients' age at diagnosis were 30 years or younger, 10,971 $(23.8 \%)$ patients were diagnosed between the age of 31 and 40 years, $11,646(25.3 \%)$ patients between the age of 41 and 50 years, 8,596 (18.7\%) patients between the age of 51 and 60 years, and $6,478(14.1 \%)$ patients' age at diagnosis was more than 60 years. More than $78.2 \%$ patients were female. The majority of the patients was white $(83.9 \%)$. A total of $20,850(45.3 \%)$ patients had at least 1 PLN. The greatest T-stage proportion was T1a $(29.2 \%)$.

The $\mathrm{LN}+$ rate was $24.8 \%, 40.8 \%, 47.5 \%, 65.9 \%$, and $78.7 \%$ for $\mathrm{T} 1 \mathrm{a}, \mathrm{T} 1 \mathrm{~b}, \mathrm{~T} 2, \mathrm{~T} 3$, and T4 stage patients, respectively. As shown in the Table 2, the mean number of PLN and LNR increased by $\mathrm{T}$ stage with each age at diagnosis. With the increasing age at diagnosis, the $\mathrm{LN}+$ rate and mean number of PLN and LNR all decreased with each T stage (all $p<0.001$ ).

As shown in Figure 1, as the T stage increases the LN+ rates also increased. Additionally, there is a reverse association between age at diagnosis and $\mathrm{LN}+$ rates with each $\mathrm{T}$ stage (all $p<0.001)$.

\section{Multivariable analysis of $\mathrm{LN}+$}

The association between age at diagnosis and LN+ was identified by logistic analysis. As shown in the Table 3, younger 
Table I Characteristic of PTC patients stratified by age at diagnosis

\begin{tabular}{|c|c|c|c|c|c|c|c|}
\hline \multirow[t]{3}{*}{ Characteristic } & \multicolumn{2}{|l|}{ Total } & \multicolumn{5}{|c|}{ Age at diagnosis (year) } \\
\hline & \multirow[b]{2}{*}{ n. } & \multirow[b]{2}{*}{$\%$} & \multirow{2}{*}{$\begin{array}{l}\leq 30 \\
\text { n. (\%) }\end{array}$} & \multirow[t]{2}{*}{$31-40$} & \multirow[t]{2}{*}{$41-50$} & \multirow[t]{2}{*}{$5 I-60$} & \multirow[t]{2}{*}{$>60$} \\
\hline & & & & & & & \\
\hline Total & 46,077 & 100 & $8,386(18.2)$ & $|0,97|(23.8)$ & II,646 (25.3) & $8,596(18.7)$ & $6,478(14.1)$ \\
\hline \multicolumn{8}{|l|}{ Sex } \\
\hline Female & 30,613 & 78.2 & $7,018(83.7)$ & $8,878(80.9)$ & 9,067 (77.9) & $6,412(74.6)$ & $4,638(71.6)$ \\
\hline Male & 10,064 & 21.8 & $1,368(16.3)$ & $2,093(19.1)$ & $2,579(22.1)$ & $2,184(25.4)$ & $\mathrm{I}, 840(28.4)$ \\
\hline \multicolumn{8}{|l|}{ Race } \\
\hline White & 38,640 & 83.9 & $7,090(84.5)$ & $9,059(82.6)$ & $9,793(84.1)$ & $7,237(84.2)$ & $7,237(84.2)$ \\
\hline Black & $\mathrm{I}, 552$ & 3.4 & $248(3.0)$ & $34 I(3.1)$ & $428(3.7)$ & $313(3.6)$ & $313(3.6)$ \\
\hline API & 5,079 & 11.0 & $852(10.2)$ & $1,344(12.3)$ & $1,232(10.6)$ & $925(10.8)$ & $925(10.8)$ \\
\hline Al & 270 & 0.6 & $81(1.0)$ & $74(0.7)$ & $59(0.5)$ & $32(0.4)$ & $32(0.4)$ \\
\hline Unknown & 536 & 1.2 & $115(1.4)$ & $153(1.4)$ & $132(1.2)$ & $81(1.0)$ & $132(1.2)$ \\
\hline \multicolumn{8}{|l|}{ T stage } \\
\hline Tla & 13,458 & 29.2 & I,665 (19.9) & $2,994(27.3)$ & $3,770(32.4)$ & $2,969(34.5)$ & $2,060(31.8)$ \\
\hline TIb & 11,682 & 25.4 & $2,240(26.7)$ & $3,030(27.6)$ & $3,033(26.4)$ & $2,065(24.0)$ & $\mathrm{I}, 274(19.7)$ \\
\hline $\mathrm{T} 2$ & 8,261 & 17.9 & $2,092(24.9)$ & $2,187(19.9)$ & $1,857(15.9)$ & $1,254(14.6)$ & $871(13.4)$ \\
\hline T3 & 9,013 & 19.6 & $1,700(20.3)$ & $2,010(18.3)$ & $2,144(18.4)$ & $1,708(19.9)$ & $\mathrm{I}, 45 \mathrm{I}(22.4)$ \\
\hline $\mathrm{T} 4$ & 3,663 & 7.9 & $689(8.2)$ & $750(6.8)$ & $802(6.9)$ & $600(7.0)$ & $822(12.7)$ \\
\hline \multicolumn{8}{|l|}{ LN status } \\
\hline Negative & 25,227 & 54.7 & $3,347(39.9)$ & $5,665(51.6)$ & $6,853(58.8)$ & $5,386(62.7)$ & $3,976(6 \mid .4)$ \\
\hline Positive & 20,850 & 45.3 & $5,039(60.1)$ & $5,306(48.4)$ & $4,793(41.2)$ & $3,210(37.3)$ & $2,502(38.6)$ \\
\hline Total LNs examined (mean $\pm S D)$ & $7.9 \pm 12.8$ & & $10.7 \pm 15.7$ & $8.2 \pm 13.1$ & $7.1 \pm 11.7$ & $6.8 \pm 11.5$ & $6.9 \pm 11.5$ \\
\hline \multicolumn{8}{|l|}{ Surgery } \\
\hline Lobectomy & 4,430 & 9.6 & 647 (7.7) & $986(9.0)$ & $1,158(9.9)$ & $914(10.6)$ & 725 (II.2) \\
\hline Total thyroidectomy & 38,103 & 82.7 & $6,784(80.9)$ & $8,598(81.7)$ & $9,716(83.4)$ & $7,278(84.7)$ & $5,467(82.8)$ \\
\hline Other surgery & 3,544 & 7.7 & $955(11.4)$ & $\mathrm{I}, 027(9.4)$ & $772(6.6)$ & $404(4.7)$ & $386(6.0)$ \\
\hline
\end{tabular}

Abbreviations: Al, American Indian or Alaska Native; API, Asian or Pacifc Islander; LN, lymph node; PTC, papillary thyroid cancer.

patients (age at diagnosis $\leq 30$ years) had higher correlation with higher $\mathrm{LN}+$ rates at each $\mathrm{T}$ stage. We used multivariate logistic regression model to evaluate whether the association between the patient's age at diagnosis and the $\mathrm{LN}+$ rates was independent of other risk factors. Patient age at diagnosis, sex, race, and surgery types were included into the adjusted model. According to the multivariate analysis, the age at diagnosis still correlated with the $\mathrm{LN}+$ rates (Table 3 ).

\section{Discussion}

In the current study, a total of 46,077 PTC patients from the SEER database were analyzed. We first identified that within each $\mathrm{T}$ stage, younger patients have an increased risk of LN+. The results were validated in multivariable analyses which including sex, race, and surgery types.

Thyroid cancer is unique among malignant tumors, because age is a vital prognostic factor in its staging systems. ${ }^{24,25}$ Our study showed that younger age at diagnosis is significantly associated with higher LN+ rates. In 2016, Zhang et $\mathrm{al}^{26}$ also made a similar finding by comparing 3 different age groups, but they ignored the influence of $\mathrm{T}$ stages. ${ }^{26}$ While some studies had reported that more advanced T stage is an important predictive factor for $\mathrm{LN}+$, it is influenced (to some extent) by the presence of the total tumor load. ${ }^{27,28}$ In our study, we were able to show the inverse association between age at diagnosis and $\mathrm{LN}+$, regardless of patient's $\mathrm{T}$ stage.

Interestingly, we also found that younger patients are associated with a higher PLN and LNR when compared to older patients at the same T stage. Several studies highlighted that LNR could be an independent predictor for the recurrence for PTC. ${ }^{29-31}$ In our analysis, the subset of patients aged 30 or younger had the highest LNR, compared with other subsets $(p<0.001)$. This finding also supports the notion that locoregional LN recurrence rate is higher for younger patients. ${ }^{32,33}$

Recurrence of PTC carries not only a higher surgical complication, but also psychological repercussions for the patient. Therefore, this present study could be interpreted as an implication for a change in surgical management of younger PTC patients. For instance, the results showed that $\mathrm{LN}+$ rate of younger patients in T1a group reached up to $37.3 \%$; the rate of older patients in T1a group was $16.8 \%$ relatively, which was consistent with the findings of Zhang et al. ${ }^{26}$ They came up with the opinion that the treatment 
Table 2 The LN+ rate and mean number of PLN and LNR stratified by T stage and age

\begin{tabular}{|c|c|c|c|c|c|c|c|c|c|c|}
\hline \multirow{2}{*}{$\begin{array}{l}\text { Age } \\
\text { (year) }\end{array}$} & \multicolumn{4}{|l|}{ Tla } & \multicolumn{4}{|l|}{ TIb } & \multicolumn{2}{|l|}{ T2 } \\
\hline & n. & LN+ NO (\%) & PLN & LNR (\%) & n. & LN+ NO (\%) & PLN & LNR (\%) & n. & LN+ NO (\%) \\
\hline$\leq 30$ & 1,664 & $620(37.3)$ & 1.5 & 18.5 & 2,237 & $\mathrm{I}, \mathrm{I} 89$ (53.2) & 2.7 & 31.0 & 2,091 & $1,275(61.0)$ \\
\hline $31-40$ & 2,988 & $847(28.3)$ & 1.0 & 14.4 & 3,030 & $\mathrm{I}, 345(44.0)$ & 1.8 & 25.4 & 2,187 & $\mathrm{I}, 079(49.3)$ \\
\hline $4 I-50$ & 3,765 & $903(24.0)$ & 0.7 & 12.1 & 3,070 & $\mathrm{I}, \mathrm{I} 44(37.3)$ & 1.4 & 21.1 & 1,856 & $790(42.6)$ \\
\hline $51-60$ & 2,967 & $609(20.5)$ & 0.5 & 9.9 & 2,065 & $690(33.4)$ & I.I & 17.4 & 1,254 & $456(36.4)$ \\
\hline$>60$ & 2,059 & $346(16.8)$ & 0.4 & 8.8 & $\mathrm{I}, 273$ & $395(31.0)$ & 1.0 & 16.8 & 871 & $320(36.7)$ \\
\hline$p^{*}$ & & $<0.001$ & $<0.001$ & $<0.001$ & & $<0.001$ & $<0.001$ & $<0.001$ & & $<0.001$ \\
\hline
\end{tabular}

Notes: *The $\mathrm{LN}+$ rates within each T stage were compared by Cochran Armitage trend tests model. The PLN and LNR within each T stage were compared by quantile regression model.

Abbreviations: LN+, lymph node positivity; LNR, lymph node ratio; PLN, positive lymph node.

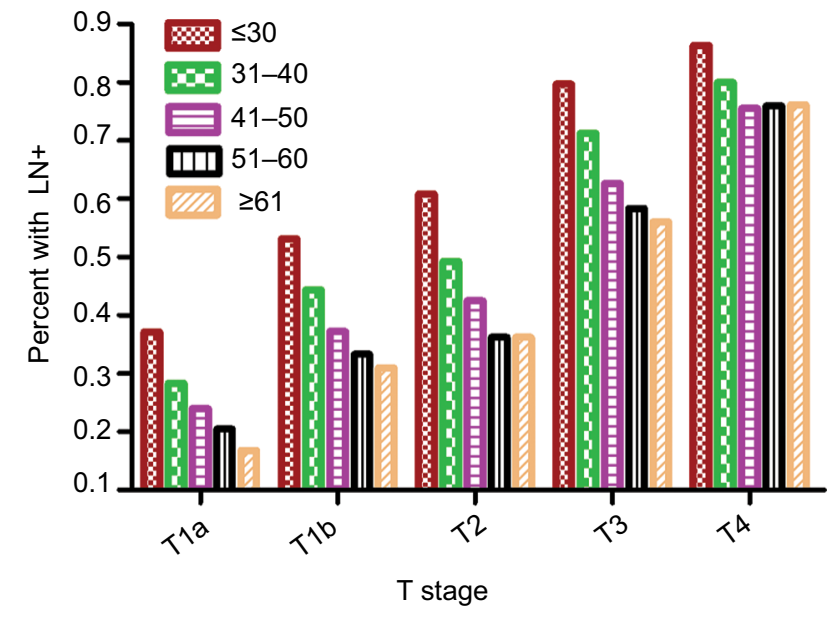

Figure I LN+ and age at diagnosis by $\mathrm{T}$ stage. Abbreviation: $\mathrm{LN}+$, lymph node positivity.

strategy of younger PTC patients could be more aggressive, with the consideration of long life span and recurrent risk. ${ }^{26}$ Ito et $\mathrm{a}^{34}$ also pointed out that younger PTC patients ( $<40$ years of age) have a higher progression risk during observation without immediate surgery, compared with older patients. Although the presence or absence of cervical LN+ does not affect mortality in younger PTC patients, locoregional LN recurrence would inevitably result in reoperation. Indeed, the rate of injuring the recurrent nerve, parathyroid glands, or their circulation during reoperation is much higher than initial surgery. ${ }^{35,36}$ With the increased risk associated with reoperations, the quality of life of these patients may be affected to some extent. Therefore, we should pay more attention to the patient's age. The very young age may not be the indicator to narrow surgical scope. On the contrary, adequate primary surgery and prophylactic/therapeutic LN dissection should be routinely performed for younger PTC patients, due to high $\mathrm{LN}+$ rates.
The reasons why the probability of $\mathrm{LN}+$ is higher in the younger group compared to the older patients had been demonstrated in other cancers. In 2012, Chang et a ${ }^{37}$ reported that early-onset ( $\leq 40$ years of age) colorectal adenocarcinoma patients were much more vulnerable to positive circumferential margins, due to signet ring cell differentiation, venous invasion, and perineural invasion. A study of melanoma suggested that the mitotic rate plays an important role in younger patients. ${ }^{38}$ With respect to PTC, Moses et $\mathrm{al}^{39}$ found multiple genetic alterations in younger patients. For instance, RET/PTC1 rearrangements, 1 key somatic genetic alteration in PTC development, were more common in childhood PTC. ${ }^{40}$ These findings may lend more support to the hypothesis that thyroid follicular cells in the young are more susceptible to promoting DNA damage than in the old. ${ }^{39,41}$ As a result, young PTC patients could be more likely to develop nonthyroid second primary cancers after treatment with radioisotope therapy. ${ }^{42}$ Moreover, there is also data showing that the incidence of capsule infiltration and vascular invasion is higher among younger patients. ${ }^{18,43-45}$ These aggressive histological features are thought to be associated with high rates of $\mathrm{LN}+{ }^{45}$

This study has several potential limitations. First, the SEER database collected information on large numbers of patients from 17 population-based cancer registries. Some clinicopathologic information may be miscoded or missed during registration process. For instance, patients' $B R A F$ gene mutations were not provided in the current dataset. Second, SEER database did not capture the preoperative data, such as neck ultrasonography and computed tomography. Therefore, we could not analyze the discrepancy between prophylactic LN dissection and therapeutic LN dissection, radical neck dissection, and modified radical neck dissection. 


\begin{tabular}{|c|c|c|c|c|c|c|c|c|c|}
\hline \multirow[b]{2}{*}{ PLN } & \multirow[b]{2}{*}{ LNR (\%) } & \multicolumn{4}{|l|}{ T3 } & \multicolumn{4}{|l|}{ T4 } \\
\hline & & n. & LN+ NO (\%) & PLN & LNR (\%) & n. & LN+ NO (\%) & PLN & LNR (\%) \\
\hline 3.3 & 39.0 & I,697 & I,355 (79.7) & 7.5 & 47.1 & 689 & $595(86.4)$ & 6.8 & 57.8 \\
\hline 2.3 & 30.0 & 2,010 & I,433 (7I.3) & 5.1 & $4 I .1$ & 748 & $600(80.0)$ & 5.1 & 51.4 \\
\hline 1.7 & 24.5 & 2,143 & $1,344(62.7)$ & 3.6 & 35.8 & 801 & $606(75.6)$ & 3.9 & 46.6 \\
\hline 1.3 & 21.3 & $\mathrm{I}, 704$ & $997(58.4)$ & 3.1 & 31.0 & 597 & $456(76.0)$ & 4.1 & 43.5 \\
\hline 1.4 & 20.5 & $\mathrm{I}, 450$ & $8 I 4(56.1)$ & 2.8 & 29.7 & 821 & $626(76.2)$ & 3.7 & 44.6 \\
\hline$<0.001$ & $<0.001$ & & $<0.001$ & $<0.001$ & $<0.001$ & & $<0.001$ & $<0.001$ & $<0.001$ \\
\hline
\end{tabular}

Table 3 The association of age and $\mathrm{LN}+$ by logistical analysis

\begin{tabular}{|c|c|c|c|c|c|c|c|}
\hline \multirow[t]{2}{*}{ T stage } & \multirow[t]{2}{*}{ Age (year) } & \multicolumn{3}{|c|}{ Unadjusted } & \multicolumn{3}{|c|}{ Adjusted } \\
\hline & & OR & $95 \% \mathrm{Cl}$ & $p$-value & OR & $95 \% \mathrm{Cl}$ & $p$-value \\
\hline \multirow[t]{5}{*}{ Tla } & $\leq 30$ & Ref & & $<0.001$ & Ref & & $<0.001$ \\
\hline & $31-40$ & 0.67 & $0.59-0.77$ & & 0.67 & $0.58-0.76$ & \\
\hline & $4 I-50$ & 0.53 & $0.47-0.60$ & & 0.51 & $0.45-0.58$ & \\
\hline & $5 I-60$ & 0.44 & $0.38-0.50$ & & 0.42 & $0.36-0.48$ & \\
\hline & $>60$ & 0.41 & $0.39-0.45$ & & 0.31 & $0.26-0.36$ & \\
\hline \multirow[t]{5}{*}{ TIb } & $\leq 30$ & Ref & & $<0.001$ & Ref & & $<0.001$ \\
\hline & $31-40$ & 0.72 & $0.63-0.78$ & & 0.68 & $0.6 I-0.76$ & \\
\hline & $4 I-50$ & 0.52 & $0.47-0.58$ & & 0.51 & $0.45-0.57$ & \\
\hline & $51-60$ & 0.44 & $0.39-0.5$ & & 0.42 & $0.37-0.47$ & \\
\hline & $>60$ & 0.40 & $0.34-0.46$ & & 0.36 & $0.31-0.42$ & \\
\hline \multirow[t]{5}{*}{$\mathrm{T} 2$} & $\leq 30$ & Ref & & $<0.001$ & Ref & & $<0.001$ \\
\hline & $31-40$ & 0.62 & $0.55-0.70$ & & 0.59 & $0.52-0.67$ & \\
\hline & $4 I-50$ & 0.47 & $0.42-0.54$ & & 0.45 & $0.39-0.51$ & \\
\hline & $51-60$ & 0.37 & $0.32-0.42$ & & 0.33 & $0.28-0.38$ & \\
\hline & $>60$ & 0.37 & $0.32-0.44$ & & 0.34 & $0.28-0.40$ & \\
\hline \multirow[t]{5}{*}{ T3 } & $\leq 30$ & Ref & & $<0.001$ & Ref & & $<0.001$ \\
\hline & $31-40$ & 0.63 & $0.54-0.74$ & & 0.60 & $0.52-0.71$ & \\
\hline & $4 I-50$ & 0.43 & $0.37-0.5$ & & 0.40 & $0.34-0.46$ & \\
\hline & $51-60$ & 0.36 & $0.31-0.42$ & & 0.32 & $0.28-0.38$ & \\
\hline & $>60$ & 0.33 & $0.28-0.38$ & & 0.30 & $0.25-0.35$ & \\
\hline \multirow[t]{5}{*}{ T4 } & $\leq 30$ & Ref & & $<0.001$ & Ref & & $<0.001$ \\
\hline & $31-40$ & 0.63 & $0.48-0.84$ & & 0.61 & $0.46-0.81$ & \\
\hline & $4 I-50$ & 0.49 & $0.37-0.64$ & & 0.46 & $0.35-0.6$ & \\
\hline & $51-60$ & 0.50 & $0.38-0.67$ & & 0.45 & $0.34-0.6$ & \\
\hline & $>60$ & 0.50 & $0.39-0.66$ & & 0.45 & $0.34-0.59$ & \\
\hline
\end{tabular}

Abbreviations: $\mathrm{Cl}$, confidence interval; $\mathrm{LN}+$, lymph node positivity; $\mathrm{OR}$, odds ratio; Ref, reference.

\section{Conclusion}

In conclusion, our study demonstrated that younger PTC patients have an increased predisposition for $\mathrm{LN}+$, across every T stage. Younger PTC patients could need more standardized treatment compared to older PTC patients with the same TNM stage. This finding could be useful for surgeons when selecting the optimal treatment for young PTC patients.

\section{Acknowledgment}

The authors thank all medical personnel of the Department of Head, Neck and Breast Surgery, The First Affiliated
Hospital of University of Science and Technology of China, Anhui Provincial Cancer Hospital, Hefei, People's Republic of China, for their technical assistance.

\section{Author contributions}

Shengying Wang conceived and designed the study. Jing Wang and Shengying Wang developed the methodology. Collection and assembly of data was done by Jing Wang and Jianjun Liu. Data analysis and interpretation was by Jing Wang, Jianjun Liu. All authors were involved with the writing, review, and/or revision of the manuscript. Admin- 
istrative, technical, or material support was provided by Jianjun Liu. The study was supervised by Shengying Wang. All authors contributed toward data analysis, drafting and critically revising the paper and agree to be accountable for all aspects of the work.

\section{Disclosure}

The authors report no conflicts of interest in this work.

\section{References}

1. Siegel RL, Miller KD, Jemal A. Cancer statistics, 2016. CA Cancer J Clin. 2016;66(1):7-30.

2. Kitahara CM, Sosa JA. The changing incidence of thyroid cancer. Nat Rev Endocrinol. 2016;12(11):646-653.

3. Altekruse S, Das A, Cho H, Petkov V, Yu M. Do US thyroid cancer incidence rates increase with socioeconomic status among people with health insurance? An observational study using SEER population-based data. BMJ Open. 2015;5(12):e009843.

4. Liu FH, Kuo SF, Hsueh C, Chao TC, Lin JD. Postoperative recurrence of papillary thyroid carcinoma with lymph node metastasis. J Surg Oncol. 2015;112(2):149-154.

5. Grant CS. Recurrence of papillary thyroid cancer after optimized surgery. Gland Surg. 2015;4(1):52-62.

6. Ito Y, Higashiyama T, Takamura Y, et al. Risk factors for recurrence to the lymph node in papillary thyroid carcinoma patients without preoperatively detectable lateral node metastasis: validity of prophylactic modified radical neck dissection. World J Surg. 2007;31(11):2085-2091.

7. Lino-Silva LS, Dominguez-Malagon HR, Caro-Sanchez CH, Salcedo-Hernandez RA. Thyroid gland papillary carcinomas with "micropapillary pattern," a recently recognized poor prognostic finding: clinicopathologic and survival analysis of 7 cases. Hum Pathol. 2012;43(10):1596-1600.

8. Xing M. BRAF mutation in papillary thyroid cancer: pathogenic role, molecular bases, and clinical implications. Endocr Rev. 2007;28(7):742-762.

9. Akslen LA, Myking AO, Salvesen H, Varhaug JE. Prognostic impact of EGF-receptor in papillary thyroid carcinoma. $\mathrm{Br} J$ Cancer. 1993;68(4):808-812.

10. Leboulleux S, Rubino C, Baudin E, et al. Prognostic factors for persistent or recurrent disease of papillary thyroid carcinoma with neck lymph node metastases and/or tumor extension beyond the thyroid capsule at initial diagnosis. J Clin Endocrinol Metab. 2005;90(10): 5723-5729.

11. Sugitani I, Kasai N, Fujimoto Y, Yanagisawa A. A novel classification system for patients with PTC: addition of the new variables of large (3 $\mathrm{cm}$ or greater) nodal metastases and reclassification during the followup period. Surgery. 2004;135(2):139-148.

12. Meyer JE, Cohen SJ, Ruth KJ, Sigurdson ER, Hall MJ. Young age increases risk of lymph node positivity in early-stage rectal cancer. $J$ Natl Cancer Inst. 2016;108(1):djv284.

13. Chao C, Martin RN, Ross MI, et al. Correlation between prognostic factors and increasing age in melanoma. Ann Surg Oncol. 2004;11(3): 259-264.

14. Anders CK, Hsu DS, Broadwater G, et al. Young age at diagnosis correlates with worse prognosis and defines a subset of breast cancers with shared patterns of gene expression. J Clin Oncol. 2008;26(20):3324-3330.

15. Patron V, Hitier M, Bedfert C, et al. Predictive factors for lateral occult lymph node metastasis in papillary thyroid carcinoma. Eur Arch Otorhinolaryngol. 2013;270(7):2095-2100.

16. Zhang L, Wei WJ, Ji QH, et al. Risk factors for neck nodal metastasis in papillary thyroid microcarcinoma: a study of 1,066 patients. J Clin Endocrinol Metab. 2012;97(4):1250-1257.
17. Malandrino P, Pellegriti G, Attard M, et al. Papillary thyroid microcarcinomas: a comparative study of the characteristics and risk factors at presentation in two cancer registries. J Clin Endocrinol Metab. 2013;98(4):1427-1434.

18. Sojak J, Sicak M, Kalis A, Slastan M. Papillary thyroid carcinoma: analysis of the central compartment's lymph nodes metastases. Acta Medica (Hradec Kralove). 2017;60(1):44-50.

19. Semrad TJ, Semrad AM, Farwell DG, Chen Y, Cress R. Initial treatment patterns in younger adult patients with differentiated thyroid cancer in California. Thyroid. 2015;25(5):509-513.

20. Shindo M, Wu JC, Park EE, Tanzella F. The importance of central compartment elective lymph node excision in the staging and treatment of papillary thyroid cancer. Arch Otolaryngol Head Neck Surg. 2006;132(6):650-654.

21. Vasileiadis I, Karatzas T, Vasileiadis D, et al. Clinical and pathological characteristics of incidental and nonincidental papillary thyroid microcarcinoma in 339 patients. Head Neck. 2014;36(4):564-570.

22. Rossi R, Roti E, Trasforini G, et al. Differentiated thyroid cancers $11-20 \mathrm{~mm}$ in diameter have clinical and histopathologic characteristics suggesting higher aggressiveness than those $\leq 10 \mathrm{~mm}$. Thyroid. 2008;18(3):309-315.

23. Anderson KJ, Youngwirth LM, Scheri RP, et al. T1a versus T1b differentiated thyroid cancers: do we need to make the distinction? Thyroid. 2016;26(8):1046-1052.

24. Haymart MR. Understanding the relationship between age and thyroid cancer. Oncologist. 2009;14(3):216-221.

25. Edge SB, Compton CC. The American Joint Committee on Cancer: the 7th edition of the AJCC cancer staging manual and the future of TNM. Ann Surg Oncol. 2010;17(6):1471-1474.

26. Zhang L, Yang J, Sun Q, et al. Risk factors for lymph node metastasis in papillary thyroid microcarcinoma: older patients with fewer lymph node metastases. Eur J Surg Oncol. 2016;42(10):1478-1482.

27. Wang P, Wang Y, Miao C, et al. Defining a new tumor dimension in staging of papillary thyroid carcinoma. Ann Surg Oncol. 2017;24(6): $1551-1556$

28. Lim YS, Lee JC, Lee YS, et al. Lateral cervical lymph node metastases from papillary thyroid carcinoma: predictive factors of nodal metastasis. Surgery. 2011;150(1):116-121.

29. Ryu IS, Song CI, Choi SH, Roh JL, Nam SY, Kim SY. Lymph node ratio of the central compartment is a significant predictor for locoregional recurrence after prophylactic central neck dissection in patients with thyroid papillary carcinoma. Ann Surg Oncol. 2014;21(1): 277-283.

30. Zheng CM, Ji YB, Song CM, Ge MH, Tae K. Number of metastatic lymph nodes and ratio of metastatic lymph nodes to total number of retrieved lymph nodes are risk factors for recurrence in patients with clinically node negative papillary thyroid carcinoma. Clin Exp Otorhinolaryngol. 2018;11(1):58-64.

31. Schneider DF, Mazeh H, Chen H, Sippel RS. Lymph node ratio predicts recurrence in papillary thyroid cancer. Oncologist. 2013;18(2): $157-162$.

32. Ito Y, Miyauchi A, Kihara M, Takamura Y, Kobayashi K, Miya A. Relationship between prognosis of papillary thyroid carcinoma patient and age: a retrospective single-institution study. Endocr $J$. 2012;59(5):399-405.

33. Kruijff S, Petersen JF, Chen P, et al. Patterns of structural recurrence in papillary thyroid cancer. World J Surg. 2014;38(3):653-659.

34. Ito Y, Miyauchi A, Kihara M, Higashiyama T, Kobayashi K, Miya A. Patient age is significantly related to the progression of papillary microcarcinoma of the thyroid under observation. Thyroid. 2014;24(1): $27-34$.

35. Kim MK, Mandel SH, Baloch Z, et al. Morbidity following central compartment reoperation for recurrent or persistent thyroid cancer. Arch Otolaryngol Head Neck Surg. 2004;130(10):1214-1216.

36. Chao TC, Jeng LB, Lin JD, Chen MF. Reoperative thyroid surgery. World J Surg. 1997;21(6):644-647. 
37. Chang DT, Pai RK, Rybicki LA, et al. Clinicopathologic and molecular features of sporadic early-onset colorectal adenocarcinoma: an adenocarcinoma with frequent signet ring cell differentiation, rectal and sigmoid involvement, and adverse morphologic features. Mod Pathol. 2012;25(8):1128-1139.

38. Sondak VK, Taylor JM, Sabel MS, et al. Mitotic rate and younger age are predictors of sentinel lymph node positivity: lessons learned from the generation of a probabilistic model. Ann Surg Oncol. 2004;11(3):247-258.

39. Moses W, Weng J, Khanafshar E, Duh QY, Clark OH, Kebebew E. Multiple genetic alterations in papillary thyroid cancer are associated with younger age at presentation. J Surg Res. 2010;160(2):179-183.

40. Nikiforov YE. RET/PTC rearrangement in thyroid tumors. Endocr Pathol. 2002;13(1):3-16.

41. Romei C, Ciampi R, Elisei R. A comprehensive overview of the role of the RET proto-oncogene in thyroid carcinoma. Nat Rev Endocrinol. 2016;12(4):192-202.
42. Brown AP, Chen J, Hitchcock YJ, Szabo A, Shrieve DC, Tward JD. The risk of second primary malignancies up to three decades after the treatment of differentiated thyroid cancer. J Clin Endocrinol Metab. 2008;93(2):504-515.

43. Miccoli P, Minuto MN, Ugolini C, et al. Papillary thyroid cancer: pathological parameters as prognostic factors in different classes of age. Otolaryngol Head Neck Surg. 2008;138(2):200-203.

44. Park HS, Jung CK, Lee SH, et al. Clinicopathologic characteristics and surgical outcomes of elderly patients with thyroid cancer. Jpn J Clin Oncol. 2014;44(11):1045-1051.

45. Mete O, Asa SL. Pathological definition and clinical significance of vascular invasion in thyroid carcinomas of follicular epithelial derivation. Mod Pathol. 2011;24(11):1545-1552.
Cancer Management and Research

\section{Publish your work in this journal}

Cancer Management and Research is an international, peer-reviewed open access journal focusing on cancer research and the optimal use of preventative and integrated treatment interventions to achieve improved outcomes, enhanced survival and quality of life for the cancer patient. The manuscript management system is completely online and includes

\section{Dovepress}

a very quick and fair peer-review system, which is all easy to use. Visit http://www.dovepress.com/testimonials.php to read real quotes from published authors. 